\title{
Adonis Vernalis a Useful Drug
}

\section{Agarwal T*}

Assistant professor, Banasthali vidhypeeth, India

${ }^{*}$ Corresponding author: Dr. Teena Agrawal, Assistant professor, Banasthali

Vidhypeeth, Niwai, India, Tel: +91-9680724243; Email: tagrawal02@gmail.com

\section{Mini Review}

Volume 2 Issue 6

Received Date: August 21, 2018

Published Date: September 03, 2018

\section{Abstract}

The TM and the AM are the main sources of the drugs in the many kinds of the civilization, the TM and the AM are the easy an safe and they are easily available in comparison to the other synthetic drugs, the TM are utilised in the, many parts of the world, due to the many kinds of the advantages of the TM and the TAM the WHO and the other parts of the world had developed the strategies for the development of the TM and the TAM well natures is the reservoirs of the many kinds of the synthetic drugs and here in this research article we are presenting the some of the aspects of the TM and the TAM in the form of the Adonis vernalis, the genus is the members of the Ranunculaceae family, the genus is herb and it is distributed in the many parts of the world where the climate is cold, in the India the genus is found in the Himalayan belts and in the adjoining area, in this review article we are presenting some of the aspects of the Adonis vernalis, the review is informative of the students of the pharmacy and the other biotechnological students.

Keywords: Adonis vernalis; Ranunculaceae Family; TM; TAM

\section{Abbreviation: TM: Transcendental Meditation}

\section{Introduction}

TM and the CAM are the easily available and they are generally used by the low and the middle class income peoples of the world. One survey of the WHO sates that in the Africa and in the several state of the Africa like the Ghana, Mali and the Indonesia the TM and the TAM were used by the treatment of the several kinds of the disorders. they were more reliable and more accurate than the other drugs of the chemical origin, the utilization of the TAM is depend on the thousands years of the experiences of the generation for the utilization of the plants as the sources of the drugs, a number of the scientific study has proved the utility of the TM and the
TAM over the other drugs. well sometime a number of the disorders are over there that they are not cured by the chemical drugs so they shift over the plant base TM drugs for the treatments due to the more safety and more accuracy of the drugs' over the other aspects [1-6].

Here in this research article we are presenting some of the aspects of the genus termed as the Adonis vernalis of the Ranunculaceae family, the species is known as the pheasant eye's, the species is also the per found in the dry deciduous tropical deciduous environment flowering herbs, the genus is also known in the steppe of the Eurasia, isolated pollution is found in the Spain and in the central Europe and the other part of the world in the cold climate. The plant is the poisonous and they are full of the several kinds of the cardiac stimulants, the main 


\section{Journal of Natural \& Ayurvedic Medicine}

phytochemical are the cardiac acid and the cardionidin [1$4]$.

In some of the cases the plant is uses as the ornamentals, the mixture of the plant parts are also used by the many kinds of the combination, these are the Bekhterev's Mixture, it is the mixture which is used Russian community for the treatment of the several kinds of the central nervous disorders. The mixture was prepared by the famous neurologists of the Russia the Vladimir Bekhterev.

\section{Uses}

The Species is used for the treatments of the several kinds of the diseases, basically the plant parts are used these are the leaves and the stalks, the active principal is the bitter glycosides, called as the Adonidin, Arcitrin, Adonidic acid, Aconotin acid, Adonidin Quercitin and Sugars. Aconidium Adonidin, the power is canary yellowed, intensely bitter tastes, and neutral reactions. The fresh plant is the irritant and vesicant, dry plants the cardiac stimulants, tonic and stimulants, it is similar in action to the digitalis, it is more active and it is active against the heart beats, it is also cardiac sedative belladonna [4-6]. The active principles are active against the dropsy, remove oedema, it slows the respiration, relieves from the thrumming headaches, perspiration, and dyspnoea. In epilepsy it is given by the potassium bromides

\section{Conclusion}

Overall this is the small review articles of the genus Adonis veranlis, we have presented the small facts and the other aspects of the genus, it informative for the students of the pharmacy and the other biochemical branches, the TM and the TAM are the basis of the curing of the diseases form the thousand of the years in the several civilizations, they are safe and easy and reliable and they are cheap than the other medical drugs the chem. The chemical drugs are hard and they have the many kinds of the side effects, they damage the all systems, and the effects of the medicines is long lasting, in other hands the plant based chemical drugs are more reliable and more authentic in the work, the species of the Adonis vernaslis is the poisonous plants as the other members of the ranunculacae, but the some of the phytochemical are useful and with the addition of the other drugs they are used in the medicines. Overall in the Indian ayurvedic system of the medicines the drugs are used for the treatment of the many disorders of the central nervous system.

\section{References}

1. Redazione D (2016) Scoperta una nuova specie vegetale rara nel Parco Sirente Velino. NewsTown.

2. Den virtuella floran: Adonis vernalis.

3. King's American Dispensatory: Adonis.

4. Bailey LH (2005) Manual of Gardening. 2n (Edn.), Project Gutenberg Literary Archive Foundation.

5. Микстура Бехтерева. LEKARSTVENNIK.RU.

6. Khory RN, Katrak NN (1981) Materia medica of India and their therapeutics. pp: 827. 